\title{
Amplification of multiple genomic loci from single cells isolated by laser micro-dissection of tissues Dan Frumkin ${ }^{1}$, Adam Wasserstrom¹, Shalev Itzkovitz ${ }^{2}$, Alon Harmelin ${ }^{3}$, Gideon Rechavi ${ }^{4}$ and Ehud Shapiro*1,2
} \begin{abstract}
Medicine, Tel Aviv University, Israel
Email: Dan Frumkin - dan.frumkin@weizmann.ac.il; Adam Wasserstrom - adam.wasserstrom@weizmann.ac.il; Shalev Itzkovitz - shalevi@wisemail.weizmann.ac.il; Alon Harmelin - alon.harmelin@weizmann.ac.il; Gideon Rechavi - Gidi.Rechavi@sheba.health.gov.il; Ehud Shapiro* - ehud.shapiro@weizmann.ac.il

* Corresponding author
\end{abstract}

Address: ${ }^{1}$ Department of Biological Chemistry, Weizmann Institute of Science, Rehovot, Israel, ${ }^{2}$ Department of Computer Science and Applied Mathematics, Weizmann Institute of Science, Rehovot, Israel, ${ }^{3}$ Department of Veterinary Resources, Weizmann Institute of Science, Rehovot, Israel and ${ }^{4}$ Sheba Cancer Research Center and the Institute of Hematology, The Chaim Sheba Medical Center, Tel Hashomer and the Sackler School of

Published: 20 February 2008

BMC Biotechnology 2008, 8:17 doi:10.1186/1472-6750-8-17
Received: 23 October 2007

Accepted: 20 February 2008

This article is available from: http://www.biomedcentral.com/I472-6750/8/17

(C) 2008 Frumkin et al; licensee BioMed Central Ltd.

This is an Open Access article distributed under the terms of the Creative Commons Attribution License (http://creativecommons.org/licenses/by/2.0), which permits unrestricted use, distribution, and reproduction in any medium, provided the original work is properly cited.

\begin{abstract}
Background: Whole genome amplification (WGA) and laser assisted micro-dissection represent two recently developed technologies that can greatly advance biological and medical research. WGA allows the analysis of multiple genomic loci from a single genome and has been performed on single cells from cell suspensions and from enzymatically-digested tissues. Laser microdissection makes it possible to isolate specific single cells from heterogeneous tissues.
\end{abstract}

Results: Here we applied for the first time WGA on laser micro-dissected single cells from stained tissue sections, and developed a protocol for sequentially performing the two procedures. The combined procedure allows correlating the cell's genome with its natural morphology and precise anatomical position. From each cell we amplified 122 genomic and mitochondrial loci. In cells obtained from fresh tissue sections, $64.5 \%$ of alleles successfully amplified to $\sim 700000$ copies each, and mitochondrial DNA was amplified successfully in all cells. Multiplex PCR amplification and analysis of cells from pre-stored sections yielded significantly poorer results. Sequencing and capillary electrophoresis of WGA products allowed detection of slippage mutations in microsatellites (MS), and point mutations in P53.

Conclusion: Comprehensive genomic analysis of single cells from stained tissue sections opens new research opportunities for cell lineage and depth analyses, genome-wide mutation surveys, and other single cell assays.

\section{Background}

Recent years have seen the birth of the single cell analysis era. With the development of technology, many research procedures and assays that were previously performed only on populations of cells have recently been applied for the study of single cells (reviewed in [1]). These include PCR [2], RT-PCR [3], comparative genomic hybridization [4], and two-dimensional electrophoresis [5]. 
The development of WGA methods (reviewed in $[6,7]$ ) has recently made it possible to analyze multiple genomic loci from single cells. Early methods were based on PCR and included degenerate oligonucleotide-primed (DOP) PCR [8], primer extension pre-amplification (PEP) [9], and ligation-mediated PCR [10]. PCR-based WGA techniques were used to amplify genomes of single cells such as blastomeres in pre-implantation genetic diagnosis (reviewed in [11,12]), lymphocytes [13], hepatocytes [14], sperm [9], oocytes [15], bone marrow cells [16,17], and even single chromosomes $[18,19]$.

Based on a combination of PEP and DOP, a commercial kit for single cell WGA was developed and used to amplify single human [20] and mouse cells (Wasserstrom, A. et al, submitted).

Recently, multiple displacement amplification using Ф29 DNA polymerase [21] was developed as an isothermal, non PCR-based method for WGA. Multiple displacement amplification results in better genomic coverage and in less biased-amplification than earlier PCR-based methods [6]. In addition, due to the low error rate of $\Phi 29$ [21], it results in less artificial mutations than PCR-based methods $[6,7]$, and this may be especially important for single cell WGA, since erroneous copying of the single template molecule in the first stages of the reaction might result in a false genotype. Multiple displacement amplification was performed on several types of single cells, including bacteria [22], fungal pores $[23,24]$, human blastomeres $[25,26]$, lymphocytes [25,27-29], buccal [30], and sperm cells [31].

All of the aforementioned single cell WGA reactions were performed either on non adhering cells (e.g. sperm, blood cells) or on cells that were obtained from tissues by mechanical disruption and/or enzymatic digestion of the tissue and re-suspension. While valuable information can be obtained via this approach, the disruption or digestion of tissues carries a disadvantage since it destroys the natural architecture and thus results in loss of information regarding the morphology and precise anatomical position of the isolated cells. This disadvantage is compounded by the fact that the structure of animal tissues is inherently complex, consisting of many different cell types in close proximity [32], and therefore biological research of tissue micro-environments requires a more subtle approach to cell isolation.

In order to preserve data regarding morphology and position, cells can be cut from stained tissue sections by microdissection, either manually or by laser assisted micro-dissection. Manual micro-dissections under an inverse microscope were used in conjunction with PCR [2] and with a PCR-based WGA method [33] to study T-cell receptor and P53 gene sequences in single human cells.

The use of laser for micro-dissection has many advantages over manual micro-manipulation and is now considered the method of choice for obtaining pure cell populations or single cells from mixed tissues [32]. Laser micro-dissection utilizes a computer-aided robot in conjunction with a microscope and a laser machine, enabling easy isolation of any desired cell with very high precision and reproducibility. Moreover, the recent incorporation of pressure catapulting in laser micro-dissection [34] allows for contactfree direct transfer of cells, thus reducing the risk for contamination.

Laser micro-dissection has been used in conjunction with a variety of downstream molecular techniques for characterization of the genome, transcriptome, and proteome of pure populations of cells in normal and pathological conditions (reviewed in [32]). The combination of laser micro-dissection followed by WGA has recently emerged as a powerful tool for large scale genomic analyses of pure populations of cells, and it was used to characterize genetic alterations in pathologic conditions such as chronic pancreatitis [35], motor neuron disease [36], and various pre-malignant [37], and malignant tumors [3740]. In these studies, the number of micro-dissected cells used as starting material for WGA ranged from 50 to 1000 s. In one study, accurate genotyping was demonstrated from as little as 100 cells [39].

The high precision of laser micro-dissecton allows for isolation of single cells and even sub-cellular components, such as nuclei, nucleus free cytoplasm, and chromosomes [32]. Laser micro-dissection followed by RT-PCR was recently used to examine expression of specific genes in single cells from frozen human brain [41-43] and muscle [44] tissues. Laser micro-dissection followed by PCR was also used on single cells from formalin-fixed, paraffinembedded (FFPE) tissues for detection of latent viral infection in human Trigeminal ganglia [45].

Here we utilized laser micro-dissection coupled to pressure catapulting followed by multiple displacement amplification for analysis of multiple genomic loci from single cells obtained from frozen mouse tissue sections. For each cell, we amplified over 100 genomic loci, including microsatellites (MS), gene exons, and mitochondrial DNA, and analyzed the amplified products by sequencing, capillary and gel electrophoresis.

\section{Results \\ Cell amplification procedure}

The procedure for amplifying genomes of laser micro-dissected single cells from frozen tissue sections is outlined 
in Figure 1A. (full protocols are presented in the materials and methods section). Tissue freezing, sectioning, and staining are performed using standard protocols. In order to minimize the risk of laser-induced damage to DNA, thin $(6 \mu \mathrm{m})$ sections are used, and micro-dissection is performed using the lowest possible energy level (determined empirically for each section, see materials and methods). Laser ablation paths are typically less than 1 $\mu \mathrm{m}$ in thickness, allowing for isolation of intact cell nuclei with contiguous cytoplasm (Figure 1B). DNA extraction and WGA are performed using the GenomiPhi DNA amplification kit reagents and protocol, with modifications. In order to reduce the risk of contamination from extraneous DNA sources, which is a major concern in single-cell procedures, stringent precautions are employed. These include prior treatment of work surfaces with DNAdestroying agents, use of dedicated pipettes and other instruments, performing DNA extraction and WGA in a restricted chamber with a UV lamp, and the use of a blank control from each tissue section in subsequent WGA and PCR reactions. Aliquots of amplified products can be used directly (without purification) as DNA templates in PCRs for analyses of specific genomic loci.

We used this procedure to amplify the genomes of 37 single cells from sections of frozen mouse tumor and normal lung tissues, which were micro-dissected and catapulted onto micro-tube caps. A total of 41 DNA extractions and WGA reactions were initially performed. However, since catapulting was not always efficient, and visual scanning of the caps could not always detect the presence of cells with certainty, the WGA products were subject to a preliminary multiplex PCR assay with primers for $4 \mathrm{MS}$ loci. Out of the 41 samples, 4 showed no amplification in any locus in the preliminary assay and were thus considered to contain no cell and were discarded. The remaining 37 samples were processed further by multiple PCRs followed by capillary electrophoresis and signal analysis. Out of the 37 cells, 20 were obtained from fresh tissue sections (i.e. micro-dissection was performed immediately following preparation of the tissue section), and 17 were obtained from pre-stored tissue sections (i.e. micro-dissection was

A

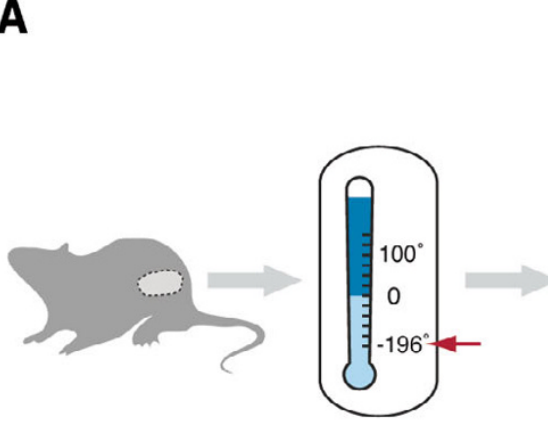

Tissue extraction Snap freezing

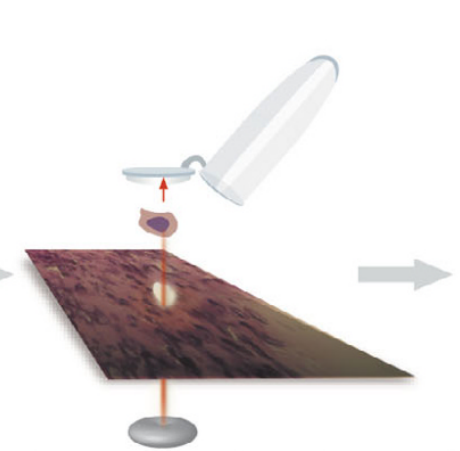

Laser micro-dissection \& catapulting

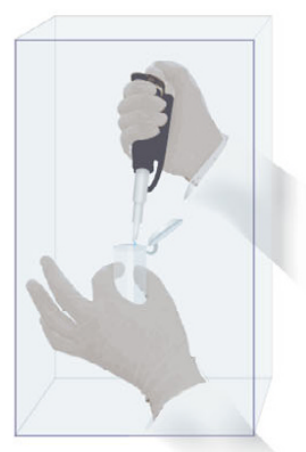

DNA extraction \& WGA in protected chamber

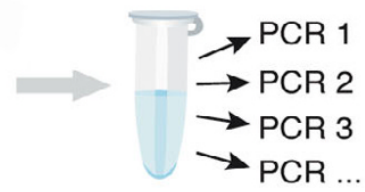

Multiple PCRs
B

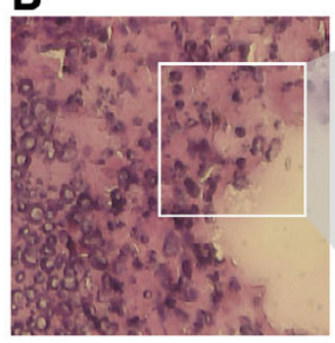

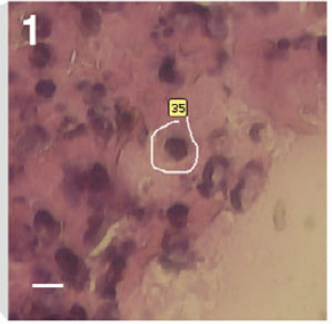

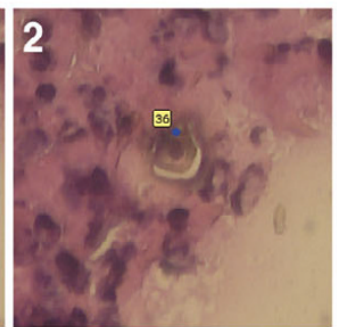

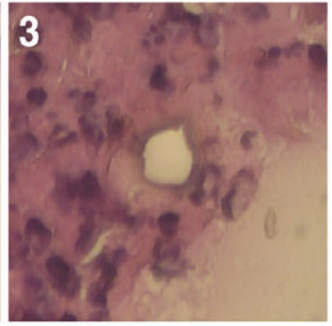

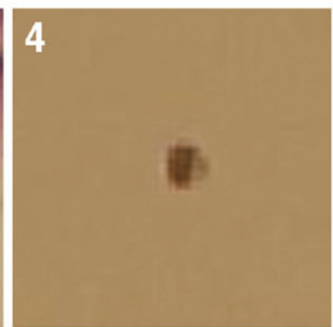

\section{Figure I}

Single cell genome amplification procedure. (A) Tissues of interest are excised and snap frozen in liquid nitrogen. After sectioning, staining, and mounting on a polyethylene membrane coated slide, a cell of interest is laser micro-dissected and catapulted into an adhesive cap of a micro-centrifuge tube. The cell is then subject to DNA extraction and WGA in a protected chamber, minimizing the chance for contamination. Aliquots of the WGA products are amplified by multiple PCRs with specific primers for analysis of multiple genomic loci. (B) Serial photographs taken during laser micro-dissection and catapulting of a single cell. The left panel shows a stained tissue section under low magnification. A portion of the tissue section is viewed under high magnification before (I) and after (2) micro-dissection, and after catapulting (3) of the single cell (bar $=6 \mu \mathrm{m})$. Inspection of the adhesive cap under low magnification (4) reveals a catapulted single cell. 
performed on sections that were prepared earlier and stored in $-80^{\circ} \mathrm{C}$ for up to several weeks). For each single cell sample, as well as for the tail clipping DNA, 122 genomic loci were amplified (following WGA). Most analyzed loci were 100-500 bp long. In order to determine if longer fragments could be analyzed, a $2.5 \mathrm{kbp}$ fragment (P53long) was also amplified.

\section{DNA size range and yield}

The size-range of WGA products was assessed by agarose gel electrophoresis. Amplified products produced a pat- tern similar to un-amplified tail clipping DNA, namely a smear ranging in size from $\sim 500$ bp upward to several kbp (Additional File 1). As expected, electrophoresis of negative control samples (i.e. no input DNA) also produced a similar pattern. However, negative control samples did not produce signals in subsequent specific PCRs (see example in Figure 2B), confirming that the observed DNA was non-specific.

Quantification of total DNA yield was performed for 8 WGA products, and yields ranged from 5.5-17 $\mu \mathrm{g}$ (mean

\section{A}

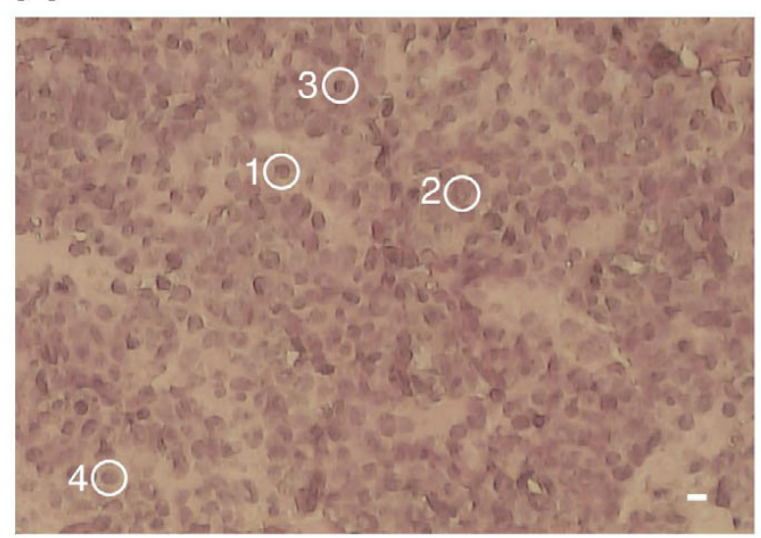

C

P53

Tail

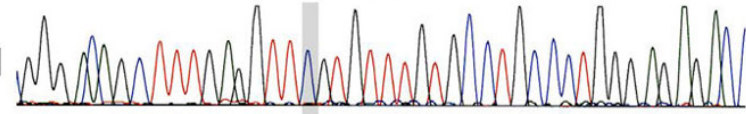

1

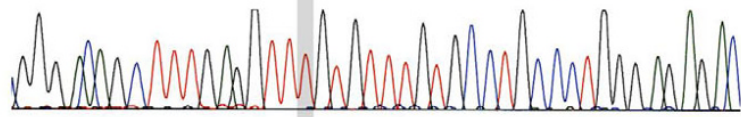

2

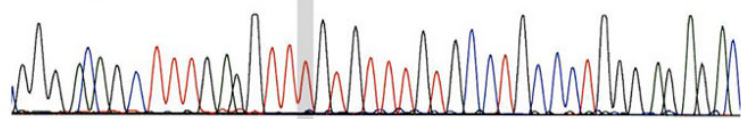

3

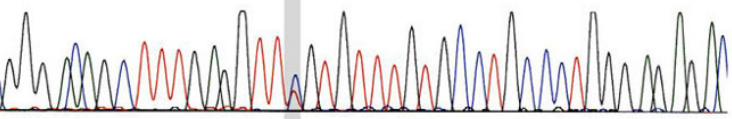

4

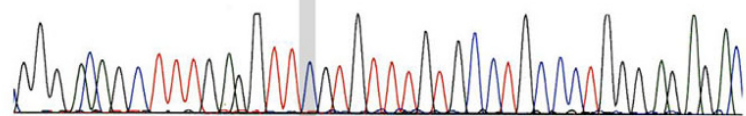

B

\section{D11MIT285}

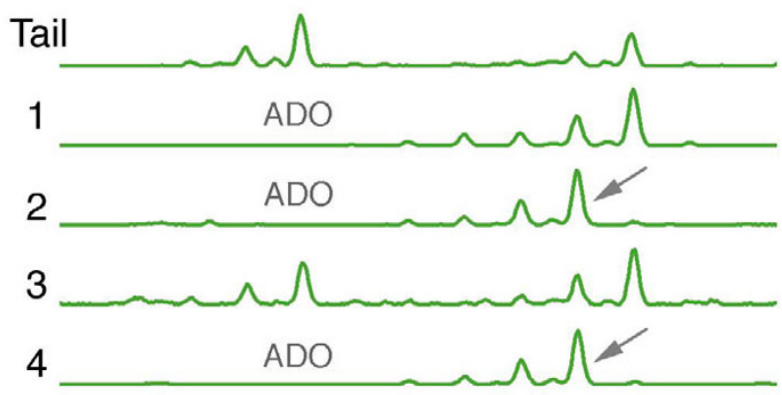

NC

\section{D}

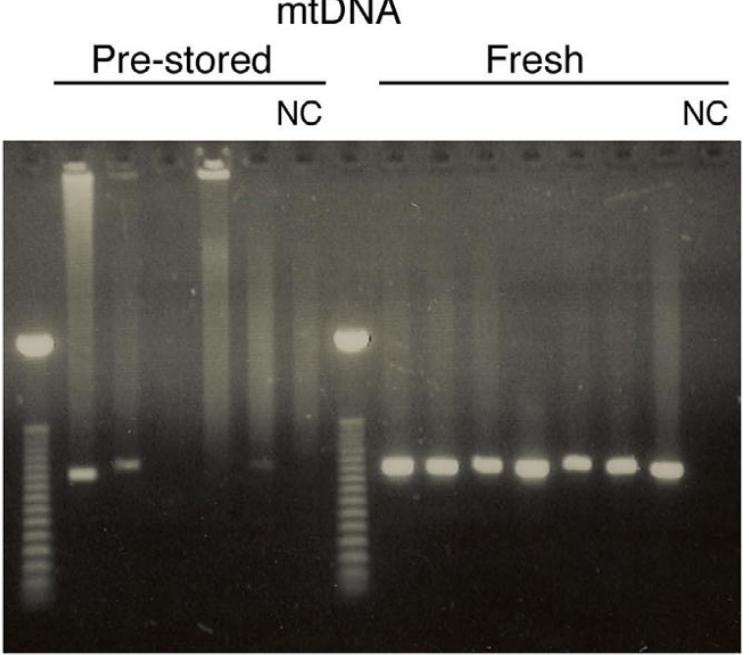

\section{Figure 2}

Amplification of multiple genomic loci from single cells. (A) Tissue section with cells $\mathrm{I}-4$ marked by white circles (bar $=6 \mu \mathrm{m})$. (B) MS locus ABI20 was analyzed by PCR amplification and capillary electrophoresis. Both paternal and maternal alleles are visible in the tail clipping sample (Tail) and in cell 3. Allelic dropout (ADO) can be seen in the short allele of cells I, 2, and 4. Slippage mutations (arrows) can be seen in the long allele of cells 2 and 4 . The negative control (NC) sample shows no amplification. (C) Sequencing of exon 8 from the P53 gene. A point mutation $(C=>T)$ can be seen in the $18^{\text {th }}$ nucleotide from the left (highlighted grey) in cells I and 2 . In cell 3 , both the normal and mutated alleles were amplified, and in cell 4 only a normal allele is visible. (D) Mitochondrial ND3 gene locus was amplified by PCR and run on an agarose gel. Amplification is successful for all cells from a fresh section, but not for all cells from a pre-stored section. 
$9.7 \mu \mathrm{g} \pm 4.2 \mu \mathrm{g}$ ). However, since non-specific DNA is present in the negative control samples, it is likely that some non-specific DNA is also present in WGA products of cells, and therefore specific amplification cannot be accurately inferred from total yield. Therefore, in order to estimate specific yield and fold-amplification, we performed quantitative real time PCRs (see below).

\section{Genomic coverage}

For each of the 37 single cell WGA products, as well as for the tail clipping DNA, 122 nuclear genomic loci (120 MS loci, and two gene segments - P53 and SRY) were amplified and analyzed. In addition, P53long and the mitochondrial ND3 locus were also amplified and analyzed (discussed below). Of the 122 loci, 32 were amplified in separate (singleplex) PCR reactions, while the remaining 90 loci were amplified by 24 multiplex PCRs, each containing primers for 3-4 MS loci. Information on each locus, including primer names, sequences (where available), basic repeat units (for MS loci), and genomic positions is presented in Table 1. All PCRs were performed with fluorescent forward primers, and capillary electrophoresis signals of PCR products were analyzed and compared to the signal from the tail clipping DNA.

In order to assess genomic coverage, we defined 4 parameters. Amplification per locus (Amp/L) was defined as amplification of at least one allele in a locus, and was calculated for all heterozygous, homozygous, and hemizygous loci (on chromosomes X and Y). Amplification failure was defined as $1-\mathrm{Amp} / \mathrm{L}$ and was a measure of the fraction of genomic loci that completely failed to amplify. Amplification per allele (Amp/A) was defined as amplification of individual alleles in a locus, and was calculated in heterozygous and hemizygous loci, but not in homozygous loci, where it is not possible to distinguish between amplification of one allele from amplification of both alleles (note that in hemizygous loci, Amp/L and Amp/A necessarily have equal values). Allele drop out (ADO) was defined as failure of amplification of one out of two alleles in a heterozygote locus. Amplification and drop out rates for each genomic locus, calculated from samples obtained from fresh tissue sections, are presented fully in Table 1, and summarized in Table 2. Loci amplified by singleplex PCR performed better than loci that were amplified by multiplex PCR, as demonstrated by significantly higher rates of $\mathrm{Amp} / \mathrm{L}(70.3 \% \pm 17.4 \%$ vs. $66.9 \% \pm 15.9 \% ; \mathrm{p}=0.043), \mathrm{Amp} / \mathrm{A}(64.5 \% \pm 16.1 \% \mathrm{vs}$ $\left.44.2 \% \pm 11.8 \% ; \mathrm{p}<10^{-7}\right)$, and lower rates of ADO $(64.2 \%$ $\pm 17.2 \%$ vs. $71.7 \% \pm 18.3 \% ; \mathrm{p}=0.055)$. Amplification and drop out rates across all loci were also calculated separately for each of the 37 single cell samples and are summarized in Table 3 (full results are presented in Additional File 2). Amplification in cells obtained from fresh tissue sections was better than in cells that were obtained from pre-stored tissue sections, as demonstrated by significantly higher rates of Amp/L, Amp/A, and lower rates of $\mathrm{ADO}$ in both singleplex and multiplex PCRs (Table 3).

Cells from fresh tissue sections that were amplified by singleplex PCR performed best, achieving Amp/L rates between 37.5 - 96.8\% (mean 70.3\% + 15.5\%), Amp/A rates between 29.7\% - 91.8\% (mean 63.5\% \pm 16.3\%), and a mean ADO rate of $64.2 \%$. In both fresh and prestored sections, ADO appeared to occur randomly, with different cells displaying dropout of the maternal or paternal allele (see example of ADO in Figure 2B). However, longer alleles (i.e. with a larger number of repeats - either paternal or maternal) had significantly higher dropout rates in comparison to their corresponding shorter alleles: out of a total of 801 ADO events, 445 (55.6\%) occurred in the long alleles and $356(44.4 \%)$ occurred in the short alleles ( $P=0.0007$; calculated for all 37 cells). This bias towards dropout of the longer allele is most likely the result of preferential amplification of the shorter allele during PCR [46].

\section{Correlation between amplification rate and physical location of loci}

We suspected that some of the observed amplification failure and ADO was a result of partial or complete loss of chromosomes as a result of truncation of nuclei during tissue sectioning. To test this possibility, we calculated the concordance of amplification status for pairs of loci on the same chromosome and compared it to the concordance of amplification status for pairs of loci on different chromosomes (in this analysis maternal and paternal homologues were considered different chromosomes).

The concordance for loci within a chromosome was $60.9 \%$ (7305 out of the 11988 same-chromosome pairs that were analyzed were both amplified or both notamplified), while the concordance for loci on different chromosomes was 56.3\% (52527/93166 pairs analyzed). In order to determine whether the higher concordance in amplification status that was observed for loci on the same chromosome was statistically significant, we performed a random permutation test. We performed 1000 permutations of all pairs of loci, and for each permutation we randomly assigned "same chromosome" and "different chromosomes" groups of pairs and calculated their respective concordance values. In all 1000 permutations, the difference in concordance rates between the groups was lower than the observed difference in the real groups, and therefore we conclude that pairs of loci on the same chromosome have significantly higher rates of concordance in amplification status than pairs of loci on different chromosomes $(\mathrm{p}<0.001)$. Further, we sought to determine whether there is a correlation between concordance in amplification status and physical distance between loci 
Table I: Loci information and amplification statistics

\begin{tabular}{|c|c|c|c|c|c|c|c|c|}
\hline & Name & Repeat & Chr & Forward primer & Reverse primer & Amp/L (\%) & Amp/A (\%) & ADO (\%) \\
\hline \multicolumn{9}{|c|}{ Loci amplified by multiplex PCRs (I-90) } \\
\hline 1 & DI6MITI89 & $A C$ & 16 & N/A & N/A & 70.0 & 45.0 & 71.4 \\
\hline 2 & D9MIT20I & TG & 9 & N/A & N/A & 75.0 & 57.5 & 46.7 \\
\hline 3 & DI2MITI82 & TG & 12 & N/A & N/A & 75.0 & 42.5 & 86.7 \\
\hline 4 & D4MIT203 & TG & 4 & N/A & $N / A$ & 65.0 & 35.0 & 92.3 \\
\hline 5 & DI7MITI80 & TG & 17 & N/A & $N / A$ & 80.0 & 45.0 & 87.5 \\
\hline 6 & DIMIT3I6 & $A C$ & $\mathrm{I}$ & N/A & N/A & 50.0 & 30.0 & 80.0 \\
\hline 7 & DIMIT206 & TG & I & $\mathrm{N} / \mathrm{A}$ & $N / A$ & 65.0 & 45.0 & 61.5 \\
\hline 8 & D9MIT250 & $A C$ & 9 & N/A & $N / A$ & 80.0 & 52.5 & 68.7 \\
\hline 9 & D4MITI7 & TG & 4 & N/A & N/A & 80.0 & 57.5 & 56.2 \\
\hline 10 & D5MIT425 & $A C$ & 5 & N/A & N/A & 55.0 & 30.0 & 90.9 \\
\hline 11 & DI8MIT222 & $\mathrm{TC}$ & 18 & N/A & N/A & 85.0 & 85.0 & 0 \\
\hline 12 & D4MITI8 & TG & 4 & N/A & $N / A$ & 70.0 & 45.0 & 71.4 \\
\hline 13 & D7MIT259 & $A C$ & 7 & $\mathrm{~N} / \mathrm{A}$ & N/A & 75.0 & 42.5 & 86.6 \\
\hline 14 & DIOMIT2I3 & TG & 10 & N/A & N/A & 75.0 & 37.5 & 100 \\
\hline 15 & D9MITI98 & TG & 9 & N/A & N/A & 70.0 & 47.5 & 64.3 \\
\hline 16 & DI0MIT95 & $A C$ & 10 & N/A & $N / A$ & 65.0 & 35.0 & 92.3 \\
\hline 17 & DI4MITI70 & TG & 14 & N/A & N/A & 60.0 & & \\
\hline 18 & DI9MIT88 & $\mathrm{GA}$ & 19 & N/A & N/A & 85.0 & 50.0 & 82.3 \\
\hline 19 & DI5MIT44 & $A C$ & 15 & N/A & N/A & 25.0 & 15.0 & 80.0 \\
\hline 20 & D5MITI46 & TG & 5 & N/A & $N / A$ & 80.0 & 52.5 & 68.7 \\
\hline 21 & D8MIT45 & $A C$ & 8 & N/A & N/A & 85.0 & 50.0 & 82.3 \\
\hline 22 & DI5MITI59 & $A C$ & 15 & N/A & N/A & 70.0 & 45.0 & 71.4 \\
\hline 23 & DI9MIT33 & $\mathrm{TC}$ & 19 & N/A & $N / A$ & 80.0 & 62.5 & 43.7 \\
\hline 24 & D6MIT36 & TG & 6 & N/A & N/A & 55.0 & 40.0 & 54.5 \\
\hline 25 & DIOMIT233 & $A C$ & 10 & N/A & N/A & 80.0 & 47.5 & 81.2 \\
\hline 26 & DIMITI32 & $\mathrm{GA}$ & 1 & N/A & N/A & 55.0 & 32.5 & 81.8 \\
\hline 27 & DI9MIT26 & TG & 19 & N/A & $N / A$ & 60.0 & 35.0 & 83.3 \\
\hline 28 & D6MIT284 & $A C$ & 6 & N/A & $N / A$ & 65.0 & 42.5 & 69.2 \\
\hline 29 & D8MIT292 & $A C$ & 8 & N/A & N/A & 70.0 & 42.5 & 78.5 \\
\hline 30 & D8MITI 20 & $A C$ & 8 & N/A & N/A & 70.0 & 45.0 & 71.4 \\
\hline 31 & D2MIT285 & TG & 2 & N/A & $N / A$ & 55.0 & 40.0 & 54.5 \\
\hline 32 & DIIMIT285 & $A C$ & 11 & N/A & N/A & 70.0 & 50.0 & 57.1 \\
\hline 33 & DIIMITI43 & $A C$ & 11 & N/A & N/A & 80.0 & 50.0 & 75.0 \\
\hline 34 & DIMITI02 & TG & 1 & N/A & N/A & 75.0 & 50.0 & 66.6 \\
\hline 35 & DIIMIT86 & TG & 11 & N/A & $N / A$ & 80.0 & 42.5 & 93.7 \\
\hline 36 & D2MIT242 & TG & 2 & N/A & $N / A$ & 65.0 & 35.0 & 92.3 \\
\hline 37 & DI4MITI26 & $A C$ & 14 & N/A & N/A & 90.0 & 57.5 & 72.2 \\
\hline 38 & DI4MITI74 & TG & 14 & N/A & N/A & 75.0 & & \\
\hline 39 & D2MIT208 & $A C$ & 2 & $\mathrm{~N} / \mathrm{A}$ & N/A & 75.0 & & \\
\hline 40 & D5MIT98 & $A C$ & 5 & $N / A$ & N/A & 25.0 & & \\
\hline 41 & DI8MITI94 & TG & 18 & N/A & N/A & 85.0 & 55.0 & 70.5 \\
\hline 42 & DI3MITI9 & GA & 13 & N/A & N/A & 80.0 & 45.0 & 87.5 \\
\hline 43 & DI7MITI22 & $A C$ & 17 & N/A & $N / A$ & 70.0 & 42.5 & 78.5 \\
\hline 44 & DI2MIT9I & $A C$ & 12 & $N / A$ & $N / A$ & 65.0 & 40.0 & 76.9 \\
\hline 45 & D5MITI0 & $A C$ & 5 & N/A & $N / A$ & 70.0 & & \\
\hline 46 & D3MIT203 & TG & 3 & $N / A$ & N/A & 90.0 & 70.0 & 44.4 \\
\hline 47 & D4MIT209 & TG & 4 & $\mathrm{~N} / \mathrm{A}$ & N/A & 60.0 & 32.5 & 91.6 \\
\hline 48 & DI5MITI6I & TG & 15 & $\mathrm{~N} / \mathrm{A}$ & $N / A$ & 85.0 & 47.5 & 88.2 \\
\hline 49 & DIMIT64 & $A C$ & I & N/A & N/A & 70.0 & 42.5 & 78.5 \\
\hline 50 & DI4MIT60 & $A C$ & 14 & N/A & $N / A$ & 70.0 & 57.5 & 35.7 \\
\hline 51 & DI2MIT59 & $A C$ & 12 & $\mathrm{~N} / \mathrm{A}$ & N/A & 70.0 & 50.0 & 57.1 \\
\hline 52 & DIMIT440 & TG & I & $N / A$ & $N / A$ & 45.0 & 32.5 & 55.5 \\
\hline 53 & D9MIT336 & $A C$ & 9 & N/A & N/A & 70.6 & 41.2 & 83.3 \\
\hline 54 & DI3MITI6 & TG & 13 & N/A & N/A & 65.0 & 25.0 & 69.2 \\
\hline 55 & D2MITI & $A C$ & 2 & N/A & N/A & 85.0 & 55.0 & 70.5 \\
\hline 56 & D4MIT348 & $A C$ & 4 & N/A & N/A & 80.0 & 45.0 & 87.5 \\
\hline 57 & $\mathrm{H} 610$ & G & 14 & ctacagtagtagcatgagaggtggtg & caaaagaatttctccttttacattgg & 85.0 & & \\
\hline 58 & Barvaz & GA & I & tggctgcacaaacaagataggag & cgaaacgtgctgtgtccattttg & 30.0 & 15.0 & 100 \\
\hline 59 & L2924 & AAAGGG & 12 & ggtgggtctctgtgggtttgag & tcatctccattagcacctgagcac & 40.0 & & \\
\hline 60 & L0382 & AG & 5 & catcgtggaaactgacccttcc & tgtgaaggcaccaaaattgagtttc & 80.0 & 57.5 & 56.2 \\
\hline 61 & D2MIT66 & $A C$ & 2 & gttgcacaggcaatcaacc & atctatcactggggctgtgc & 40.0 & & \\
\hline 62 & D2MIT4II & $A C$ & 2 & acactcacaactacgagataaagcc & aggtcattagggctgtcttcc & 52.9 & 26.5 & 100 \\
\hline 63 & DIMITIOOI & $A C$ & I & ttgtgtgtagtacagtgttggtgg & tggttcctgacatcaatctcc & 85.0 & & \\
\hline 64 & D2MITI00 & $A C$ & 2 & gtgttcctaaggttgtattttggc & gaaatttgacaattgctaggtgc & 80.0 & 50.0 & 75.0 \\
\hline
\end{tabular}


Table I: Loci information and amplification statistics (Continued)

\begin{tabular}{|c|c|c|c|c|c|c|c|c|}
\hline 65 & DIMIT426 & $\mathrm{AC}$ & $T$ & ctgccatccactacttggtg & caaatgatacagtggaaacccc & 85.0 & 60.0 & 58.8 \\
\hline 66 & L262I & $A C$ & 12 & atgaaaagatgcaaattccagcac & aggctgccatacactcctccag & 80.0 & 70.0 & 25.0 \\
\hline 67 & L3464 & AAG & 16 & ttcagtctcctcccatctgtgc & cgatgtgttgtgcattggttcc & 70.0 & 40.0 & 85.7 \\
\hline 68 & L2454 & AGTC & 17 & ttccccacatcgctgtaaatgg & tggcctgagacaaaagcctagc & 84.6 & 61.5 & 54.5 \\
\hline 69 & M4 & AAG & 6 & acggcgtgccttttcattttac & cttgtcccttgctgctcatctg & 65.0 & 42.5 & 69.2 \\
\hline 70 & L2462 & AAAGC & 3 & ccagagatacatagtgagaccatgacg & ctgatggtcctgctggcttttag & 65.0 & 55.0 & 30.7 \\
\hline 71 & L623I & AGC & 5 & actccccacagaggtcaccaag & gctggctctcctgtagacattgg & 65.0 & 47.5 & 53.8 \\
\hline 72 & LI053 & AAAG & 7 & aggcctatctttgccgcagac & gcctggcattgtatctcaggttc & 35.0 & 27.5 & 42.8 \\
\hline 73 & L2492 & AAAGG & 5 & acccacatagaggcagggtgag & tcacagactgagttgaaggagaagg & 40.0 & 25.0 & 75.0 \\
\hline 74 & MI6 & AAGC & 10 & ttcaggtagatacatcagacctgtgg & aagtcttgggggaacagtcgag & 75.0 & 45.0 & 80.0 \\
\hline 75 & MI9 & TCTCT & 10 & tgtgcagggaagactggatctg & tgatcatctcaagtgttttgtcacg & 75.0 & 45.0 & 80.0 \\
\hline 76 & $\mathrm{H} 34 \mathrm{I}$ & G & 12 & gcctaggacataaggatggtagattg & taggttgatatgtgagtgcaaagaaag & 25.0 & & \\
\hline 77 & LI463 & ССТСТТСТТ & 16 & catcaccccagctctttgaatc & tcccagaaatatgttgaacttcagtc & 40.0 & 22.5 & 87.5 \\
\hline 78 & M2 & $A C$ & 5 & aggccacacctgagcttttagc & tcttcccaatcaccgattcacc & 70.0 & & \\
\hline 79 & M7 & AAG & 6 & tccagccttcagtaggcacagg & ggacaactaccacaaaattccaagg & 60.0 & 37.5 & 75.0 \\
\hline 80 & MII & TTTC & II & aaactttatcaggaggaaagtgaaagc & ggccacatcacttttgaagctg & 35.0 & 20.0 & 85.7 \\
\hline 81 & M6 & AGA & I & ggacaaaccaatgtgttcttgtgtg & tgagcagcatctctggagaacag & 80.0 & 40.0 & 100 \\
\hline 82 & M8 & TCC & $x$ & aagttgcccagaggggaatgtc & ttcatggaaataaacatgcttctgg & 40.0 & 40.0 & \\
\hline 83 & MI8 & AAGCA & 3 & agaccaggcaccaccagtcaag & cgtaaagaacgcagataaagcttgc & 65.0 & & \\
\hline 84 & MI5 & СТAT & 18 & acttggaggaggacggtgagag & tttacttagtgctcagcttggaagg & 65.0 & 45.0 & 61.5 \\
\hline 85 & L294I & AG & I & gtaggcctgcaaagcaggagtg & ggtctgggctagggtgggaag & 75.0 & 47.5 & 73.3 \\
\hline 86 & DIMIT495 & TC...AC & I & ccaccttgctccaaaagaaa & tctgagaggctgccacaata & 75.0 & 47.5 & 73.3 \\
\hline 87 & L7262 & AAC & 2 & ctgagttggcaggcaaaatgtg & ttgcctctcaagcctttgtgtc & 71.4 & 46.4 & 70.0 \\
\hline 88 & L4I63 & GCCTCCT & 2 & tggctggactgagattccacag & caaaccctttagcagagcatgg & 70.0 & 47.5 & 64.3 \\
\hline 89 & MI3 & СTTT & 14 & gggcataaattgtttgtcgcttg & gtgtgactgctcgcttcccatc & 60.0 & 35.0 & 83.3 \\
\hline 90 & MI7 & AGAA & $x$ & tctcatggatgaacctataaacaaagg & aattgaaaagtgtgagcccatgc & 35.0 & 35.0 & \\
\hline
\end{tabular}

Loci amplified by singleplex PCRs (91-124)

\begin{tabular}{|c|c|c|c|c|c|c|c|c|}
\hline 91 & IDT5 & $\mathrm{TC}$ & 13 & gagccaactctatgggctgagg & catagcaaccccatccttcctg & 80.0 & 60.0 & 50.0 \\
\hline 92 & IDT7 & AG & 13 & gcccctgaatcttgaactggtg & ccccaaaagtagccaacagtgg & 80.0 & 55.0 & 62.5 \\
\hline 93 & IDT8 & GA & 6 & catacagtgccccctccctaag & agctttcctgaggggcattctc & 90.0 & 70.0 & 44.4 \\
\hline 94 & IDTI2 & AG & 4 & gaatagcatcaccgcactgcac & agaggtccgttgcatctgttgg & 80.0 & 42.5 & 93.7 \\
\hline 95 & IDTI3 & $A C$ & 2 & ggagggttttaaatagggaatgtgaag & tgcaaagtgcccttctttgacc & 90.0 & 60.0 & 66.6 \\
\hline 96 & IDTI4 & $\mathrm{TC}$ & 14 & cgaactctttgcctcctgtatttcc & cagaatctggacaccacaacattacac & 95.0 & 62.5 & 68.4 \\
\hline 97 & LXI & $A$ & $x$ & ccgaggatctttcctcgtttattg & ttcatgctgtcccagaccagtg & 80.0 & 80.0 & \\
\hline 98 & LX6 & G & $x$ & tggcagccatagttcattcagg & agtaggggaaatggcagggttg & 80.0 & 80.0 & \\
\hline 99 & LX7 & C & $x$ & catgtgaaagtggtgtcaacttgg & cagtatttggtggcctttcatcg & 50.0 & 50.0 & \\
\hline 100 & LXIO & GA & $\mathrm{x}$ & cccgacttcctgcttcttttcc & cattccttcatcccctccttcc & 80.0 & 80.0 & \\
\hline 101 & LXII & A & $x$ & cctttctgcttggggttctgtg & ggaaaaggaagtgcagggagag & 75.0 & 75.0 & \\
\hline 102 & LX33 & GA & $\mathrm{x}$ & tgaactctggtcaatcatctcacag & ccccaaagcatttacacatataggg & 75.0 & 75.0 & \\
\hline 103 & LX39 & GT & $\mathrm{x}$ & ttgtcccaagagttccacaagg & accagtatggccaaaggagcag & 80.0 & 80.0 & \\
\hline 104 & LX46 & $A$ & $x$ & ggaaggggaaacaaccaaaatg & cccacttgtagaacagtttgccttc & 70.0 & 70.0 & \\
\hline 105 & $\mathrm{LX} 12$ & $\mathrm{~T}$ & $x$ & ttctagtccatccagccettcc & ggggcgtgctgtaccttaattg & 75.0 & 75.0 & \\
\hline 106 & $\mathrm{LX} 35$ & $\mathrm{TC}$ & $x$ & atgagcaggaggaggagtgctg & aagagcgagaaatgacgcaagg & 80.0 & 80.0 & \\
\hline 107 & $\mathrm{LX} 40$ & $A C$ & $\mathrm{x}$ & aggaccccatctcttggtttgg & gccagccttgaggaatacaacg & 40.0 & 40.0 & \\
\hline 108 & $\mathrm{LX} 27$ & A & $\mathrm{x}$ & caactcagttcccccatgacac & tccaaaaaccaggcaattctcc & 80.0 & 80.0 & \\
\hline 109 & $\mathrm{LX} 42$ & GT & $x$ & tcatagaccccaaactggctgtc & tggagcagcctagtggaattgtc & 80.0 & 80.0 & \\
\hline 110 & $\mathrm{LX} 43$ & $\mathrm{CA}$ & $x$ & tcttttgtggatgccagagtcaag & tggatatgggcattgaatcttcg & 75.0 & 75.0 & \\
\hline III & LXI8 & $\mathrm{T}$ & $x$ & gaagagcctcagctgcaaggac & cgccaatcaaccccatttttag & 75.0 & 75.0 & \\
\hline 112 & LX47 & GT & $x$ & gagccaacaaggtccctgaaac & ggggagcatttgctgaattacc & 75.0 & 75.0 & \\
\hline 113 & LXI7 & G & $x$ & caccatcagcctttcccaagac & cctctctggctttgctttctgg & 65.0 & 65.0 & \\
\hline 114 & $\mathrm{LX} 20$ & $\mathrm{~T}$ & $x$ & ggcatcctcgctattccatgag & caaatgctgtggaattcaccaatg & 80.0 & 80.0 & \\
\hline 115 & $\mathrm{LX} 25$ & GA & $x$ & tattgcctgtggaagggattgg & ggcaatgccatttggctcttag & 35.0 & 35.0 & \\
\hline 116 & $\mathrm{LX} 28$ & $\mathrm{TC}$ & $x$ & tggattccgatattcaacaatacatcc & ctgagcactctgcgagcaaaac & 50.0 & 50.0 & \\
\hline 117 & $\mathrm{LX} 34$ & СТ & $x$ & cagcaaaaacaggtggctgtg & aatgcagggctcaggaaatgag & 35.0 & 35.0 & \\
\hline 118 & $\mathrm{LX} 32$ & AG & $\mathrm{x}$ & atgttcaatgcatcccctctcc & tgatggggactcagagttttcg & 45.0 & 45.0 & \\
\hline 119 & LX3। & GA & $x$ & tgatgccatccaaaatcatcatc & gccaggtaggaagatggtcagtc & 45.0 & 45.0 & \\
\hline 120 & $\mathrm{LX} 24$ & $A$ & $x$ & cggggacattccacgttagttc & gcttatggtggattccctgtgc & 40.0 & 40.0 & \\
\hline 121 & SRY & & $Y$ & gtgagaggcacaagttggc & ctctgtgtaggatcttcaatc & 85.0 & 85.0 & \\
\hline 122 & P53short & & II & Ttcttactgccttgtgctggtc & aagaggtgactttggggtgaag & 85.0 & & \\
\hline 123 & P53long & & II & Acacctgatcgttactcggcttgtc & ttcactacaaaggctgagctgg & 64.7 & & \\
\hline 124 & ND3 & & Mt & acgtctccatttattgatgagg & gaggttgaagaaggtagatggc & 100.0 & & \\
\hline
\end{tabular}

Amp/L - amplification per locus

Amp/A - amplification per allele. Calculated for heterozygous and hemizygous loci. ADO - allele drop out. Calculated for heterozygous loci

N/A - Not available 
Table 2: Mean amplification and dropout rates for genomic loci

\begin{tabular}{llll}
\hline & Amp/L (\%) & Amp/A (\%) & ADO (\%) \\
\hline Singleplex & $70.3 \pm 17.4$ & $64.5 \pm 16.1$ & $64.2 \pm 17.2$ \\
Multiplex & $66.9 \pm 15.9$ & $44.2 \pm 11.8$ & $71.7 \pm 18.3$ \\
P value & 0.043 & $8.3 \times 10^{-8}$ & 0.055
\end{tabular}

Each $A m p / L, A m p / A$, and $A D O$ value represents mean \pm standard deviation of the corresponding distribution of values presented in Table I (excluding P53long and ND3).

$P$ values represent Kolmogorov-Smirnov goodness-of-fit hypothesis test scores for comparisons between the respective singleplex and multiplex distributions.

on the same chromosome. For this purpose we analyzed the amplification status of 24 MS loci with known physical locations on the $\mathrm{X}$ chromosome. We created a matrix of physical Euclidean distances between the loci along the chromosome, and a second matrix of concordance of amplification between these same loci. The correlation of these matrices was -0.08 , indicating that smaller physical distances were associated with higher amplification concordance, although this result was not significant relative to a permutation test (performed by permuting one of the matrices 1000 times and re-computing the correlation coefficient, $\mathrm{p}=0.13$ ). Together, these results support the possibility that truncation of nuclei during tissue sectioning resulted in loss of genetic information.

\section{Specific yield and fold amplification}

For calculating specific DNA yield and fold-amplification, quantitative real-time PCR was performed on 8 cells from fresh tissue sections, using primers for 4 genomic MS loci and the mitochondrial ND3 locus. The specific genomic loci were chosen because they were single copy, hemizygous loci, from chromosomes $\mathrm{X}$ and $\mathrm{Y}$, that amplified successfully in all 8 cells in regular PCRs. Hemizygosity was important because fold-amplification can be measured accurately in hemizygous loci, where all amplification necessarily stems from the single genomic copy, in contrast to heterozygous or homozygous loci, where amplification can stem from either two or just one of the genomic copies (due to ADO). Quantitative real-time
PCR results are presented in Table 4. Single copy genomic loci were amplified to $3.8 \times 10^{5}-1.2 \times 10^{6}$ copies (mean $\left.6.9 \times 10^{5} \pm 3.4 \times 10^{5}\right)$, and specific DNA represented $18.4-60.7 \%$ (mean $44.2 \% \pm 12.1 \%$ ) of total DNA (specific + non-specific). However, this calculation of specific DNA percentage and yield represented only genomic loci that amplified successfully (loci used for quantitative realtime PCR were chosen for this purpose because of their successful amplification in regular PCRs). Therefore, in order to calculate the corresponding un-biased figure for all loci, the figure for specific DNA percentage was multiplied by the mean Amp/A for all loci (63.5\%), yielding a mean corrected specific DNA percentage of $28.0 \%$.

These results indicate that WGA products from single cells consisted of $\sim 72 \%$ non-specific DNA and $\sim 28 \%$ specific DNA, and that the specific DNA contained 700000 copies of each successfully-amplified locus.

\section{$P 53$ gene locus}

A 240 bp fragment (P53short), containing exon 8 of the mouse P53 gene was successfully amplified from 17/20 cells from fresh tissue sections, and from 5/17 cells from pre-stored tissue sections. Amplified fragments were purified and sequenced (Figure 2C), and mutations were detected in some samples (see below). In order to see whether a longer fragment of the same locus could also be amplified in cells that showed successful amplification of P53short, a second PCR was performed, with primers for P53long, a $2.5 \mathrm{kbp}$ fragment encompassing the P53short fragment. 12/22 cells showed successful amplification of the P53long fragment. Of these, 9 were from fresh sections and 3 were from pre-stored sections.

\section{Mitochondrial DNA}

For each cell, we amplified by PCR and analyzed by gel electrophoresis the ND3 mitochondrial locus. Amplification was successful for all 20 cells from fresh tissue sections, and for $13 / 17$ cells from pre-stored tissue sections (Figure 2D). The ND3 locus was also amplified in 8 cells by quantitative real-time PCR. ND3 was amplified with greater efficiency than genomic loci, achieving a mean

Table 3: Mean amplification and dropout rates for cells

\begin{tabular}{lllllll}
\hline & \multicolumn{3}{c}{ Singleplex } & & Multiplex \\
& Amp/L & Amp/A & ADO & Amp/L & Amp/A & ADO \\
Fresh & $70.3 \pm 15.5$ & $63.5 \pm 16.3$ & $64.2 \pm 27.6$ & $66.9 \pm 12.9$ & $45.4 \pm 10.5$ & $71.9 \pm 13.9$ \\
Pre-stored & $36.5 \pm 15.5$ & $32.9 \pm 14.2$ & $75.5 \pm 28.4$ & $40.4 \pm 12.6$ & $24.7 \pm 7.5$ & $85.3 \pm 3.8$ \\
P score & $2.1 \times 10^{-5}$ & $3.6 \times 10^{-5}$ & 0.48 & $2.1 \times 10^{-5}$ & $2.1 \times-5$ & $3.7 \times 10^{-4}$
\end{tabular}

Each result represents mean percentage \pm standard deviation of the corresponding distribution that is presented in Additional file 2 . For fresh cells, mean amplification values differ slightly from corresponding rates in table I, because absence of uncounted samples (due to positive signals in the corresponding negative controls) tend to affect the average slightly differently in horizontal vs. vertical calculation (i.e. when calculated per cell vs. per locus).

P scores represent Kolmogorov-Smirnov goodness-of-fit hypothesis test scores for comparisons between the respective distributions. 
Table 4: Percentage and fold-amplification of specific DNA determined by real-time PCR

\begin{tabular}{|c|c|c|c|c|c|c|c|c|c|}
\hline \multirow[b]{2}{*}{ Cell } & \multicolumn{5}{|c|}{ Real-time PCR concentration $(\mathrm{ng} / \mu \mathrm{l})$} & \multirow[b]{2}{*}{ 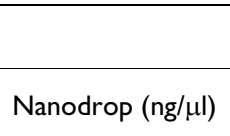 } & \multirow[b]{2}{*}{ Specific genomic (\%) } & \multirow[b]{2}{*}{ Specific mitochondrial (\%) } & \multirow[b]{2}{*}{ Fold-amplification (copies) } \\
\hline & $X I$ & $\times 6$ & XII & SRY & ND3 & & & & \\
\hline 1 & 133 & 22.8 & 2.36 & 78.0 & 81.8 & 112 & 52.7 & 73 & $1.1 \times 10^{6}$ \\
\hline 2 & 27.1 & 10.7 & 7.1 & 41.6 & 293 & 51 & 42.4 & 574 & $4.3 \times 10^{5}$ \\
\hline 3 & 25.6 & 33.8 & 4.5 & 48.1 & 193 & 58 & 48.2 & 332 & $5.5 \times 10^{5}$ \\
\hline 4 & 21.8 & 23.8 & 17.9 & 75.1 & 151 & 77 & 45.0 & 196 & $6.9 \times 10^{5}$ \\
\hline 5 & 25.9 & 40.4 & 2.3 & 67.5 & 266 & 56 & 60.7 & 475 & $6.7 \times 10^{5}$ \\
\hline 6 & 22.2 & 6.14 & 13.9 & 36.7 & 55.5 & 46 & 42.8 & 120 & $3.9 \times 10^{5}$ \\
\hline 7 & 30.4 & 67.5 & 1.8 & 153 & 1006 & 144 & 43.8 & 698 & $1.2 \times 10^{6}$ \\
\hline 8 & 8.06 & 12.6 & 2.7 & 13.5 & 882 & 50 & 18.4 & 1764 & $3.8 \times 10^{5}$ \\
\hline \multicolumn{7}{|c|}{ Cells I-8 (mean \pm std $)$} & $44.2 \pm 12$ & $529 \pm 545$ & $6.9 \times 10^{5} \pm 3.4 \times 10^{5}$ \\
\hline
\end{tabular}

specific yield of 529\% (Table 4). However, in contrast to the hemizygous genomic loci, which were known to be present at a single copy in the template DNA, the copy number of mitochondrial genomes was not known in either the single cell samples or in the tail clipping DNA that was used for the dilution series. Therefore, it was not possible to calculate precise fold - amplification for mitochondrial DNA.

\section{Mutations}

In this study, the mouse used for experimentation was a mismatch-repair deficient mouse, with a knockout of the MLH1 gene (see materials and methods). These mice are known to accumulate somatic mutations in MS loci in an accelerated rate [47]. In order to analyze somatic mutations, for each cell the length of amplified MS loci was compared to the length of the corresponding MS loci amplified from DNA obtained from the tail clipping of the same animal (obtained by standard procedures and without WGA). Replication slippage mutations (insertions or deletions of basic repeat units) were detected as differences in the size of the fragments (Figure 2B). A total of 994 slippage mutations were detected, representing $39.6 \%$ of all amplified alleles. Quantitative analysis of these mutations was performed allowing for reconstruction of the cells' lineage tree (Frumkin, D. et al., submitted), and for estimation of the depth of the cells (Wasserstrom, A. et al., submitted). Analysis of the genomic sequences from exon 8 of the P53 gene revealed no mutations in the normal lung epithelium cells, whereas 9 tumor cells were found to have the same specific point mutation, which is known to be associated with cancer (Frumkin, D. et al., submitted). In several tumor cells, sequencing revealed the presence of both the normal and mutated alleles (Figure 2C), indicating that the cells were heterozygote at the P53 locus.

\section{Contamination}

All single cell samples that were catapulted from a particular tissue section were subsequently accompanied in all procedures by a negative control sample that consisted of a $100 \mu \mathrm{m}^{2}$ piece of empty membrane catapulted from the same tissue section. A total of 8 negative control samples (from 8 different tissue sections) were produced, and each was amplified by 58 PCRs (24 multiplex + 34 singleplex). A positive signal was detected in 8 out of the 564 PCRs that were performed on negative control samples. Upon detection of each positive signal in a negative control sample, the primer mix was replaced by a fresh mix prepared from stock solutions, and in all cases subsequent PCRs of negative control samples with the fresh mixes did not produce any signal. These results indicate that negative control samples were not contaminated with DNA, and that the observed signals in PCRs of negative control samples were a result of contamination of the primer mixes during liquid handling.

\section{Discussion and Conclusion}

The amplification procedure described here can be optimized further, to allow for more efficient cell capture, higher amplification rates, and lower ADO rates. However, even with best optimization, it is unlikely that laser micro-dissected cells from tissue sections could achieve the same amplification rates as fresh cells from cell suspensions. Truncation of some cells during sectioning, and direct damage to DNA from the laser beam represent intrinsic limitations of the method that are not likely to be overcome. However, lower levels of amplification are not necessarily expected to pose a serious problem for potential applications that are centered on large scale genomic surveys.

\section{Cell capture}

Laser catapulting into adhesive caps was relatively inefficient as $60 \%$ of catapulting attempts resulted in cells landing back onto the slide surface at a nearby location, rather 
than sticking to the caps. This did not pose a significant problem for us because the processes of laser micro-dissection, catapulting, and detection of failed catapulting attempts were very fast compared to upstream and downstream procedures. Typically, cells were micro-dissected and catapulted within less than a minute and visual scanning of slides after catapulting enabled the detection of failed attempts within seconds. This amount of time was insignificant compared to the time spent on tissue sectioning and staining, WGA, PCR, capillary electrophoresis, and signal analysis. Initially, we spent a considerably longer time visually scanning caps after catapulting in order to verify the presence of cells. This procedure, however, was discontinued when it became apparent that it was not necessary. Out of 41 cells that were catapulted and that "passed" visual inspection of the slides, only 4 $(9.7 \%)$ failed to amplify in subsequent WGA, indicating that visual scanning of slides was sufficient in order to detect $>90 \%$ of catapulting failures. In addition, the cells that were analyzed came from large, homogenous populations, and therefore cells that failed to catapult could easily be substituted in the experiment with nearby similar cells. Therefore, low catapulting efficiency did not represent a bottleneck in our application and we did not attempt to optimize this process. However, in applications where the desired cells are part of rare populations (e.g. micro-metastatic cells), attempting to increase catapulting efficiency may be beneficial. One possibility for achieving this could be by minimizing the distance from the cap to the tissue section, as capturing is more efficient across small distances. This step, however, carries the risk of contamination from unnoticed contact between the cap and tissue. A second option would be to use nonadhesive caps filled by lysis buffer, instead of adhesive caps. Liquid may be more efficient than solid adhesive material in capturing catapulted cells, but this approach would require manual filling of each individual cap immediately prior to catapulting if evaporation of the small volume of liquid is to be avoided. Alternatively, catapulting energy and focus could be changed from default values and optimized for best efficiency. Increased energy level is expected to provide more kinetic energy to catapulted cells, but it also carries the risk of causing damage to DNA. By performing such optimization steps and with experienced handling, it should be possible, according to the manufacturer of the laser machine, to achieve catapulting efficiency of over $90 \%$.

\section{Effects of pre-storage and multiplexing on amplification rates}

Amplification success rates were significantly higher in cells obtained from freshly prepared tissue sections compared to cells obtained from sections that were mounted and stored at $-80^{\circ} \mathrm{C}$ for several weeks prior to WGA. In the absence of nucleases, DNA is expected to be stable for years, and therefore the reduction in amplification rates was most probably caused indirectly, by biochemical processes in the tissues during storage. DNA degradation in immunohistochemically stained slides was previously reported to occur via oxygen radicals as a result of exposure to air [33]. Another possibility might be increased nuclease activity during storage due to temperature changes or other unidentified technical problems. Amplification rates in singleplex PCRs were significantly higher in comparison to multiplex PCRs for both fresh and prestored samples. Poorer performance of multiplex PCR on single cell WGA products was reported previously [26], and likely results from preferential amplification of loci in multiplex PCR compounded by differing copy numbers of different genomic targets in WGA products. Preferential amplification often occurs in multiplex PCR as a result of different efficiencies of different primer pairs and from creation of primer dimers, which are more likely to occur as the number of primers increases [48]. This problem is compounded when the template DNA contains variable copy numbers at different loci. Although multiple displacement amplification is the method that results in the most balanced genome amplification to date, it still suffers from up to 6 fold amplification representation differences between loci [49]. Therefore, in multiplex PCR on multiple displacement amplification products, when primer pairs with relatively low efficiency act on genomic loci with relatively low copy numbers, the result might be amplification failure or ADO. This problem could be circumnavigated by optimization of the multiplex PCR, by changing primer sequences, concentrations, and cycling conditions. However, such optimization might prove more labor intensive and time consuming than performing singlplex PCRs. In this study, the amount of WGA product from each cell was sufficient for 120 PCRs. Furthermore, as the volume of the multiple displacement amplification reaction can be scaled up, there is no theoretical limit to the amount of PCRs that could be performed on each cell.

\section{Comparison of amplification rates with other studies}

Comparison of the efficiency of the single cell WGA presented here with results from previous studies is hampered by the lack of a universally accepted nomenclature. The term ADO was defined here and elsewhere $[26,33,50]$ as failure of amplification of one out of two alleles in a heterozygous locus. By this definition, failure of amplification of both alleles in a heterozygous locus does not count as ADO, but rather counts as "amplification failure". However, other studies $[30,51]$ have defined ADO as the failure of amplification of any of the 2 alleles in a heterozygous locus, and by this definition failure of amplification in 2 alleles is counted as 2 ADO events, and the term "amplification failure" is not used. Yet other studies used the term ADO without providing any definition, 
making it difficult to interpret their results. Similar ambiguity exists in other commonly used terms, such as "amplification efficiency", "genomic coverage", and "allele calling", therefore necessitating careful scrutiny and adjustment of values when comparing results from different studies.

WGA was previously performed on many types of single cells from cell suspensions, with varying success rates, depending on the specific method used and on the specific cell type that was analyzed. Of all WGA methods, multiple displacement amplification gives the most complete genomic coverage [6], and is considered the most effective method to date [7]. Multiple displacement amplification was recently demonstrated on single buccal cells, achieving 90\% Amp/L and 72\% Amp/A [30]; on single blastomeres, achieving 90.3\% Amp/L, 67.5\% amp/A, and $25.5 \%$ ADO [26]; and on single lymphoblasts, achieving $89.5 \% \mathrm{Amp} / \mathrm{L}, 78 \% \mathrm{Amp} / \mathrm{A}$, and $25.8 \% \mathrm{ADO}$ $[29,52]$. These amplification rates are higher than the corresponding rates presented here $(70.3 \% \mathrm{Amp} / \mathrm{L}, 63.5 \%$ Amp/A, 64.2\% ADO from fresh tissue sections).

To the best of our knowledge, multiple displacement amplification was not previously performed on single cells from frozen tissue sections, and consequently it is currently unknown whether fresh suspended cells are generally expected to amplify better than cells from frozen tissue sections. However, a handful of studies have performed PCR directly (without WGA) on single cells from frozen tissue sections, achieving rates of amplification that are similar to or slightly lower than the rates presented here. In one study, manually micro-manipulated single cells from a human skin section were amplified with $37 \% \mathrm{Amp} / \mathrm{A}$ [2]. In another study, Laser micro-dissected single keratinocytes were amplified with $70 \%$ $\mathrm{Amp} / \mathrm{L}, 52.5 \% \mathrm{Amp} / \mathrm{A}$, and 50\% ADO [53].

Unlike formalin fixation, which causes degradation [54] and cross-linking [33] of DNA, and thereby resulting in poor amplification from single cells [33], freezing of tissues is not expected to significantly damage DNA. However, tissue sectioning might cause truncation of nuclei, and it has been estimated that when processing single cells from $6 \mu \mathrm{m}$ sections, truncation leads to a loss of $10-20 \%$ of the genetic material [33]. In this study, cells with an average nucleus diameter of $\sim 5 \mu \mathrm{m}$ were isolated from $6 \mu \mathrm{m}$ sections, and since cells are not precisely aligned on the horizontal plain, it is indeed likely that truncation of nuclei contributed to loss of genetic information. This possibility gains strength from the observation that the concordance of amplification status in loci that were located on the same chromosome was significantly higher than the concordance of amplification status in loci that were located in different chromosomes, and from the negative correlation that was observed between physical distances between loci on the same chromosome and amplification concordance. The problem of genetic loss due to nuclei sectioning could be overcome by using thicker sections, but this might result in some samples containing more than a single nucleus. In addition, the use of thicker sections requires higher laser energy levels for micro-dissection, and since laser energy might damage DNA (see below), it would require the use of larger "safety" margins around micro-dissected nuclei.

The use of laser energy for micro-dissection might also contribute to loss of genetic material by causing direct damage to DNA. According to the manufacturer of the laser machine, such damage is expected to be confined to an area immediately adjacent to the ablation path, with the width of the damaged area not more than $50 \%$ of the ablation path width (e.g. a damaged strip with a width of $0.5 \mu \mathrm{m}$ on either side of a $1 \mu \mathrm{m}$ wide ablation path). For this reason, ablation path widths should be minimized by using the lowest energy levels possible for micro-dissection.

Considering this, it is likely that WGA of laser micro-dissected cells from tissue sections can achieve somewhat lower amplification rates than WGA of fresh cells from suspension. Despite this, it should be noted that lower rates of amplification are not expected to pose a significant problem in most future applications of the work presented here. Until the present, most single cell WGA studies have been motivated by applications in preimplantation genetic diagnosis, and since ADO represents the greatest challenge in this field (potentially resulting in misdiagnosis of embryos), much emphasis was put on reducing $\mathrm{ADO}$ rates to the minimum. However, the potential applications of single cell WGA from tissue sections are not in pre-implantation genetic diagnosis, but rather in research areas where large scale genomic surveys are employed at the single cell level, such as in the emerging fields of cell lineage [14,55,56], reviewed in [57], cell depth [56], (Wasserstrom, A. et al, submitted), and stem cell dynamics [58] analyses. These fields are not focused on comparing genotypes of cells in any particular locus, but rather extract information from a general genetic comparison performed across multiple loci. In these types of researches, the rate of ADO has little significance, and the most important parameter may be the total amount of genetic information that can be obtained from each cell in a given amount of time, labor, or money.

\section{Possible applications}

As stated above, genome amplification of single cells from laser micro-dissected tissues can be very beneficial for cell lineage and depth analyses. Indeed, the motivation for the work presented here came from our wish to expand the 
capabilities of the method for cell lineage analysis that was recently developed by our group [55]. Previously, invivo cell lineage reconstruction and depth estimation was performed on non-adherent cells or on cells isolated by enzymatic digestion of tissues [14], (Wasserstrom, A. et al, submitted). With the development of the protocols presented here, it became possible to use laser micro-dissection for analyzing lineage relations between specific cells in tissue micro-environments. We used mutational information from the genomes of the 37 micro-dissected cells described here to reconstruct their lineage tree. Analysis of this reconstructed tree revealed that the cancer cells shared a common clonal origin and that they were significantly deeper (i.e. had undergone more cell divisions) than adjacent normal lung epithelial cells. It also revealed that growth of the tumor occurred in a coherent manner, without significant cell motility (Frumkin, D. et al., submitted).

Correlating between a single cell's genome and its' morphology and precise position in the tissue micro-environment may also open new research possibilities in the study of the genetics of various physiological and pathological processes. For example, in the physiological context, it could be used to determine whether genetic alterations underlie phenotypic changes associated with aging, or to determine the exact spatial and temporal pattern of generation of receptors in immune cells and meiotic recombination in germ cell precursors. It could also be used to study genetic changes underlying many pathological processes, and especially cancer. For example, this work may advance understanding of the initiation and progression of pre-malignant and cancerous lesions, by allowing for comprehensive correlations to be made between the phenotype of various abnormal cells and possible mutations in various proto-oncogenes.

Tumor tissues are composed of heterogeneous cell populations. A minority of tumor cells are "cancer stem cells" that may be important for resistance to therapy and metastasis [59]. The tumor microenvironment contains various non-malignant cells such as lymphocytes and fibroblasts that interact with the malignant cells [60]. The ability to analyze, at the single cell level, the genomes of various malignant and non-malignant cells is expected to increase our understanding of cancer.

The amplification rate of the mitochondrial ND3 locus was very high in this study, as all 20 cells from fresh sections showed amplification. This result is not surprising considering the high copy number of mitochondrial genomes relative to the single copy of hemizygous genomic loci in a single cell. In addition, the ND3 locus achieved a high specific yield of $>500 \%$ in the quantitative real-time PCR, possibly as a result of the high effi- ciency of the multiple displacement amplification on circular DNA templates, relative to linear fragments. This result indicates that the method may allow for efficient screening of cells for the presence of other circular DNA species, including genomes of intracellular pathogens. Such a screening may be used to investigate the precise pattern of the spread of pathogens and to uncover cell populations that harbor latent viral infections.

\section{Methods \\ Experimental animals}

Mlh1+/- mice were obtained from Michael Liskay (OHSU, described in [47]) and were maintained at our institute under a dual genetic background ( $\mathrm{C} 57 \mathrm{Bl} / 6$ and $129 \mathrm{SvEv})$. All work was done under the Weizmann Institute of Science IACUC approval. Mlh1+/- C57Bl/6 and Mlh1+/$129 \mathrm{SvEv}$ were mated to yield an Mlh1-/- animal that was used for the experiment. At the age of 9 months, upon signs of illness, the animal was sacrificed by $\mathrm{CO}_{2}$ asphyxiation. Examination revealed a round tumor mass (diameter $-9 \mathrm{~mm}$ ) in the thoracic cavity and two additional tumor foci in the right and left lungs. Tissues from the large tumor mass and from both lungs were removed, snap frozen in liquid nitrogen, and stored in $-80^{\circ} \mathrm{C}$ until use.

\section{Preparation of tissue sections}

Frozen mouse tissues were cut in a cryostat microtome (CRYOTOME - LEICA CM3050 S) at $-20^{\circ} \mathrm{C}$ to $6 \mu \mathrm{m} \mathrm{sec}$ tions and mounted on membrane-coated slides (PALM MembraneSlides - $1 \mathrm{~mm}$ PEN membrane covered). Tissue sections were stained with Hematoxylin and Eosin solutions (Sigma-Aldrich) according to the following protocol (all solutions were ice-cold): 2 minutes in $70 \%$ ethanol followed by several rinses in double-distilled water (DDW), 2 minutes in Hematoxylin, 2 minutes in tap water pre-filtered with $0.2 \mu \mathrm{m}$ disposable filter units (Schleicher \& Schuell), several brief rinses in Eosin, several rinses in $70 \%$ ethanol, several rinses in $100 \%$ ethanol. Following staining, tissue sections were dried at room temperature for 5 minutes prior to laser micro-dissection.

\section{Laser assisted micro-dissection}

Laser micro-dissection was performed using the PALM MicroBeam micro-dissection apparatus (PALM Microlaser Technologies). Parameters for laser energy, focus, and speed were adjusted individually for every tissue section, such that dissection was performed with minimal laser energy. The minimal energy level was determined by performing continuous laser micro-dissection with decreasing energy levels on a portion of the section adjacent to the area destined for cell isolation. Single cell samples were catapulted using default catapulting energy and focus parameters into adhesive caps of $200 \mu \mathrm{l}$ micro-tubes (PALM Microlaser Technologies). In $60 \%$ of catapulting 
attempts the catapulted cells failed to adhere to the adhesive caps of the micro-centrifuge tubes, and instead were observed to land back onto the tissue sections at nearby locations. In these cases, the micro-tubes were discarded and the micro-dissected cells were not processed further. In 41 cases (representing 40\% of attempts) catapulting appeared to be successful, and for these a visual inspection of the caps was performed. Cells that adhered to the central, relatively flat area of the caps were detected, but cells that adhered to the peripheral concave areas of the cap could not always be identified with certainty. In order to verify successful catapulting, a preliminary PCR assay was performed on all 41 samples following DNA extraction and WGA.

\section{DNA extraction}

DNA extraction from single cells was based on the protocol of the GenomiPhi DNA amplification kit (Amersham Biosciences) for extraction of DNA from blood cells, with modifications. For each sample, $4 \mu$ lysis buffer (composed of $50 \%$ PBS and 50\% of the following solution: 400 mM KOH, 100 mM DTT, 10 mM EDTA, 3\% Tween-20) was applied directly to the adhesive cap containing the catapulted cell sample. The tube was then closed and the sample was placed on ice for 15 minutes. After lysis, neutralization was performed by adding $2 \mu$ neutralization buffer (400 mM HCL, 600 mM Tris HCL, PH 0.6). DNA extraction from the mouse tail clipping was performed with the Wizard SV Genomic DNA purification system (Promega).

\section{Whole genome amplification}

WGA was performed in the original micro-centrifuge tube containing extracted DNA using the GenomiPhi DNA amplification kit (Amersham Biosciences) according to the manufacturer's protocol, with all reaction volumes increased six-fold (final volume - $120 \mu \mathrm{l}$ ).

\section{Preliminary PCR assay}

A preliminary multiplex PCR was performed (with primers for D6MIT36, D10MIT233, D1MIT132, M2 - see Table 1) for each WGA product. Reagents and thermal cycling conditions were the same as for the other PCR reactions (see below). Out of 41 samples, 4 showed no amplification in any locus and were thus considered to contain no cell and were discarded. The remaining 37 samples were processed further by multiple PCRs followed by capillary electrophoresis and signal analysis.

\section{Contamination control}

Prior to work, gloves and work surfaces were pre-rinsed with DNA away solution (Molecular BioProducts). The microscope plate was cleaned with Iso-propanol and the cryotome surfaces were cleaned with acetone. Cutting of tissue sections was performed using a new blade for each section. For staining, a new set of solutions was prepared and used for each section.

Negative control samples for WGA were prepared for each mounted and stained slide from a $100 \mu \mathrm{m}^{2}$ piece of empty polyethylene membrane containing no mouse tissue. DNA extraction and WGA were performed in a protected workstation (Cleanspot PCR workstation - COY laboratory products) that was used solely for these procedures, with a set of pipettes that were used solely for these procedures and that were kept inside the workstation at all times. Prior to DNA extraction and WGA, the contents of the workstation (including pipettes) were exposed to UV light for one hour.

\section{Primer design, PCR amplification, and electrophoresis}

A total of 129 genomic loci and the ND3 mitochondrial locus were amplified for each single cell sample and for the tail clipping DNA. Five loci that failed to amplify in tail clipping DNA were not analyzed further. The remaining 124 loci are listed in Table 1. Loci 1-90 were amplified in multiplex reactions, each containing 3-4 primer pairs, and loci 91-124 were amplified in singleplex reactions. Loci 1-56 were amplified using commercial primers (ABI PRISM $^{\circledast}$ Mouse Mapping Primers v.1.0.) and therefore the sequences for these loci are not available. Sequences of primers for locus 121 (SRY) were obtained from [61], and sequences of primers for locus 124 (ND3) were obtained from [62]. Sequences of primers for all other loci were designed using Primer3 [63] with the following parameters changed from default: Primer size $=20,22,27$ ( $\mathrm{mini}-$ mum, optimal, maximum); Primer $\mathrm{Tm}=62^{\circ} \mathrm{C}, 65^{\circ} \mathrm{C}$, $68^{\circ} \mathrm{C}$ (minimum, optimal, maximum); Max Tm difference $=2.5^{\circ} \mathrm{C}$; CG clamp $=1$. All PCR reactions were carried out in a volume of $25 \mu \mathrm{l}$ including $1.2 \mu \mathrm{l}$ unpurified WGA product as template, $0.2 \mu \mathrm{M}$ of each primer, $0.2 \mathrm{mM}$ of each dNTP (BIOLINE), 0.625U of Thermo-Start DNA Polymerase (ABgene), and $2.5 \mu \mathrm{l}$ of $10 \times$ PCR buffer (ABgene). Thermal cycling conditions for all reactions (except for the long range PCR reaction) were : (i) $15 \mathrm{~min}$ utes $95^{\circ} \mathrm{C}$, (ii) 35 cycles of: 1 minute $95^{\circ} \mathrm{C}, 1$ minute $58^{\circ} \mathrm{C}, 1$ minute $72^{\circ} \mathrm{C}$, (iii) 15 minutes $72^{\circ} \mathrm{C}$.

Thermal cycling conditions for the long range PCR reaction (with P53long primers) were: (i) 15 minutes $95^{\circ} \mathrm{C}$, (ii) 35 cycles of: 30 seconds $95^{\circ} \mathrm{C}, 30$ seconds $58^{\circ} \mathrm{C}, 3$ minutes $72^{\circ} \mathrm{C}$, (iii) 15 minutes $72^{\circ} \mathrm{C}$.

Most amplified products were run on a capillary electrophoresis machine: $0.75-1 \mu \mathrm{l}$ of a PCR product was added to a $14 \mu \mathrm{l}$ solution containing 1 part GeneScan $500 \mathrm{LIZ}$ size standard (Applied Biosystems) and 24 parts HiDi Formamide (Applied Biosystems), mixed thoroughly, and run on an ABI prism 3130xl Genetic Analyzer machine (Applied Biosystems). Fragment analysis was performed 
using the GeneMapper v3.7 software accompanying the machine.

Amplified products of P53short, P53long, ND3, and SRY loci were run on a gel: $5 \mu \mathrm{l}$ of each PCR product was mixed with $3 \mu \mathrm{l}$ of Blue/Orange 6X loading dye (Promega), loaded to a well of a gel containing $0.8-1.2 \%$ agarose (Agarose Low EEO - Hispanagar, Spain), and stained with $50 \mu \mathrm{g}$ Ethidium Bromide (amresco). DNA ladders used were 50 bp DNA step ladder (Promega) and 1 KB DNA ladder (NEB). Products were subject to electrophoresis at $100 \mathrm{~V}$ for 1 hour and gels were photographed with ImageMaster (Pharmacia Biotech).

\section{Robotic automation}

We used a programmable laboratory robot (TECAN Genesis) augmented with a PCR machine (Biometra TRobot) to perform the liquid handling for PCR, the PCR itself, and the sample preparation for the capillary and gel electrophoresis.

\section{DNA yield and size range}

Prior to calculation of yield, WGA products were purified by alcohol precipitation, according to the protocol provided in the manual of the GenomiPhi DNA Amplification Kit (Amersham Biosciences). DNA concentrations of purified WGA products (in $\mathrm{ng} / \mu \mathrm{l}$ ) were measured with the Nanodrop ND-1000 Spectrophotometer (Nanodrop technologies), and results were multiplied by $120 \mu \mathrm{l}$ (total volume of each WGA reaction), yielding total DNA yields. WGA products of cells 1-8 were analyzed for size-range of products by gel electrophoresis using the reagents and conditions that are outlined above (in "Primer design, PCR amplification, and electrophoresis").

\section{Quantitative real-time PCR}

Quantitative real-time PCR was performed with the MyiQ single color Real-Time PCR Detection System (Bio-Rad). Each reaction contained $1 \mu$ l of WGA product as template, $0.2 \mu \mathrm{M}$ of each forward and reverse primer, $12.5 \mu \mathrm{l}$ SYBR Green Supermix (Bio-Rad), and DDW to a total volume of $25 \mu \mathrm{l}$. Serial dilutions of tail-clipping DNA were used for the dilution series. Thermal cycling conditions for all reactions were 10 minutes $95^{\circ} \mathrm{C}$ followed by 45 cycles of: 1 minute $95^{\circ} \mathrm{C}, 1$ minute $58^{\circ} \mathrm{C}, 1$ minute $72^{\circ} \mathrm{C}$.

Percentage of specific genomic DNA for each cell was calculated by dividing the mean specific DNA concentration for genomic loci (X1, X6, X11, and SRY) as measured by real-time PCR, by the total (specific + non-specific) DNA concentration, as measured in the Nanodrop spectrophotometer. Percentage of specific mitochondrial DNA was calculated similarly from the results for the ND3 locus. Fold-amplification was calculated for genomic loci only by multiplying the specific genomic DNA percentage by the total DNA yield, and dividing the result by the approximate weight of a single mouse diploid genome ( $6 \mathrm{pg})$.

\section{Statistical analysis}

$\mathrm{P}$ values for all comparisons of Amp/L, Amp/A, and ADO rates between multiplex vs. singleplex loci and between fresh vs. pre-stored tissue sections were calculated using the Kolmogorov-Smirnov goodness-of-fit hypothesis test as implemented by MATLAB (MathWorks, Natick, Massachusetts, United States). P value for the comparison between ADO rates of long vs. short alleles was calculated using the binomial distribution with parameter 0.5.

\section{Authors' contributions}

DF performed the experiments and drafted the manuscript. AW, SI, and AH performed the experiments. GR and ES coordinated the experiments and helped to draft the manuscripts. All authors read and approved the final manuscript.

\section{Additional material}

\section{Additional File 1}

Gel electrophoresis of whole genome amplification products. Click here for file

[http://www.biomedcentral.com/content/supplementary/14726750-8-17-S1.doc]

\section{Additional File 2}

Amplification and dropout rates for cells. Click here for file

[http://www.biomedcentral.com/content/supplementary/14726750-8-17-S2.doc]

\section{Acknowledgements}

We would like to thank Itai Kela and Ulrich Sauer for their extensive practical and conceptual help with laser micro-dissection.

The work was supported by Kahn Family Foundation, by The Israel Academy of Science and Humanities (Bikura), by The Yeshaya Horowitz association through the center for Complexity Science, by The Research Grant from Dr. Mordecai Roshwald, by The Grant from Kenneth and Sally Leafman Appelbaum Discovery Fund, by The Estate of Karl Felix Jakubskind and by The Clore Center for Biological Physics. Ehud Shapiro is the Incumbent of The Harry Weinrebe Professorial Chair of Computer Science and Biology and of The France Telecom - Orange Excellence Chair for Interdisciplinary Studies of the Paris "Centre de Recherche Interdisciplinaire" (FTO/ CRI). Flight Attendants Medical Research Institute (FAMRI). G.R. holds the Djerassi Chair in Oncology at the Sackler Faculty of Medicine, Tel-Aviv University.

\section{References}

I. Sims CE, Allbritton NL: Analysis of single mammalian cells onchip. Lab Chip 2007, 7:423-440.

2. Brauns TC, Goos M: Micromanipulation of single cells from tissue imprints is an alternative to laser-assisted microdissection. J Cutan Pathol 2005, 32:46 I-466. 
3. Kobashi H, Yaoi T, Oda R, Okajima S, Fujiwara H, Kubo T, Fushiki S: Lysophospholipid receptors are differentially expressed in rat terminal schwann cells, as revealed by a single cell rt-PCR and in situ hybridization. Acta Histochem Cytochem 2006, 39:55-60.

4. Langer S, Geigl JB, Gangnus R, Speicher MR: Sequential application of interphase-FISH and CGH to single cells. Lab Invest 2005 , 85:582-592.

5. Harwood MM, Christians ES, Fazal MA, Dovichi NJ: Single-cell protein analysis of a single mouse embryo by two-dimensional capillary electrophoresis. J Chromatogr A 2006, I I 30: I 90-1 94.

6. Lasken RS, Egholm M: Whole genome amplification: abundant supplies of DNA from precious samples or clinical specimens. Trends Biotechnol 2003, 21:531-535.

7. Panelli S, Damiani G, Espen L, Micheli G, Sgaramella V: Towards the analysis of the genomes of single cells: further characterisation of the multiple displacement amplification. Gene 2006, 372:1-7.

8. Telenius H, Carter NP, Bebb CE, Nordenskjold M, Ponder BA, Tunnacliffe A: Degenerate oligonucleotide-primed PCR: general amplification of target DNA by a single degenerate primer. Genomics 1992, 13:718-725

9. Zhang L, Cui X, Schmitt K, Hubert R, Navidi W, Arnheim N: Whole genome amplification from a single cell: implications for genetic analysis. Proc Natl Acad Sci U S A 1992, 89:5847-585 I.

10. Saunders RD, Glover DM, Ashburner M, Siden-Kiamos I, Louis C Monastirioti M, Savakis C, Kafatos F: PCR amplification of DNA microdissected from a single polytene chromosome band: a comparison with conventional microcloning. Nucleic Acids Res 1989, I 7:9027-9037.

II. Coskun S, Alsmadi O: Whole genome amplification from a single cell: a new era for preimplantation genetic diagnosis. Prenat Diagn 2007, 27:297-302.

12. Peng $\mathrm{W}$, Takabayashi $\mathrm{H}$, lkawa $\mathrm{K}$ : Whole genome amplification from single cells in preimplantation genetic diagnosis and prenatal diagnosis. Eur J Obstet Gynecol Reprod Biol 2007, |3 I: |3-20.

13. Hu DG, Webb G, Hussey N: Aneuploidy detection in single cells using DNA array-based comparative genomic hybridization. Mol Hum Reprod 2004, 10:283-289.

14. Salipante SJ, Horwitz MS: Phylogenetic fate mapping. Proc Nat Acad Sci U S A 2006, 103:5448-5453.

15. Sanchez-Garcia JF, Benet J, Gutierrez-Mateo C, Luis Seculi J, Monros $\mathrm{E}$, Navarro J: Multiple mutation analysis of the cystic fibrosis gene in single cells. Mol Hum Reprod 2005, II:463-468.

16. Klein CA, Schmidt-Kittler O, Schardt JA, Pantel K, Speicher MR, Riethmuller G: Comparative genomic hybridization, loss of heterozygosity, and DNA sequence analysis of single cells. Proc Natl Acad Sci U S A 1999, 96:4494-4499.

17. Gangnus R, Langer S, Breit E, Pantel K, Speicher MR: Genomic profiling of viable and proliferative micrometastatic cells from early-stage breast cancer patients. Clin Cancer Res 2004, 1 0:3457-3464

18. Liu X, Wang H, Li Y, Tang Y, Liu Y, Hu X, Jia P, Ying K, Feng Q, Guan J, Jin C, Zhang L, Lou L, Zhou Z, Han B: Preparation of single rice chromosome for construction of a DNA library using a laser microbeam trap. J Biotechnol 2004, 109:217-226.

19. Thalhammer S, Langer S, Speicher MR, Heckl WM, Geigl JB: Generation of chromosome painting probes from single chromosomes by laser microdissection and linker-adaptor PCR. Chromosome Res 2004, I 2:337-343.

20. Fiegler H, Geigl JB, Langer S, Rigler D, Porter K, Unger K, Carter NP, Speicher MR: High resolution array-CGH analysis of single cells. Nucleic Acids Res 2007, 35:e I5.

21. Dean FB, Hosono S, Fang L, Wu X, Faruqi AF, Bray-Ward P, Sun Z, Zong Q, Du Y, Du J, Driscoll M, Song W, Kingsmore SF, Egholm M, Lasken RS: Comprehensive human genome amplification using multiple displacement amplification. Proc Natl Acad Sci U S A 2002, 99:526I-5266.

22. Marcy Y, Ouverney C, Bik EM, Losekann T, Ivanova N, Martin HG Szeto E, Platt D, Hugenholtz P, Relman DA, Quake SR: Dissecting biological "dark matter" with single-cell genetic analysis of rare and uncultivated TM7 microbes from the human mouth. Proc Natl Acad Sci U S A 2007, 104: I 1889- I I 894.

23. Gadkar V, Rillig MC: Application of Phi29 DNA polymerase mediated whole genome amplification on single spores of arbuscular mycorrhizal (AM) fungi. FEMS Microbiol Lett 2005, 242:65-7I.

24. Gadkar V, Rillig MC: Suitability of genomic DNA synthesized by strand displacement amplification (SDA) for AFLP analysis: genotyping single spores of arbuscular mycorrhizal (AM) fungi. J Microbiol Methods 2005, 63:157-164.

25. Hellani A, Coskun S, Tbakhi A, Al-Hassan S: Clinical application of multiple displacement amplification in preimplantation genetic diagnosis. Reprod Biomed Online 2005, 10:376-380.

26. Ren Z, Zhou C, Xu Y, Deng J, Zeng H, Zeng Y: Mutation and haplotype analysis for Duchenne muscular dystrophy by single cell multiple displacement amplification. Mol Hum Reprod 2007, 13:43I-436.

27. Hellani A, Coskun S, Benkhalifa M, Tbakhi A, Sakati N, Al-Odaib A, Ozand P: Multiple displacement amplification on single cell and possible PGD applications. Mol Hum Reprod 2004, 10:847-852.

28. Handyside $A H$, Robinson MD, Simpson RJ, Omar MB, Shaw MA Grudzinskas JG, Rutherford A: Isothermal whole genome amplification from single and small numbers of cells: a new era for preimplantation genetic diagnosis of inherited disease. Mol Hum Reprod 2004, 10:767-772.

29. Spits C, Le Caignec C. De Rycke M, Van Haute L, Van Steirteghem A Liebaers I, Sermon K: Optimization and evaluation of single-cell whole-genome multiple displacement amplification. Hum Mutat 2006, 27:496-503.

30. Renwick PJ, Trussler J, Ostad-Saffari E, Fassihi H, Black C, Braude P, Ogilvie CM, Abbs S: Proof of principle and first cases using preimplantation genetic haplotyping--a paradigm shift for embryo diagnosis. Reprod Biomed Online 2006, I3: I I0-1 I9.

31. Jiang Z, Zhang X, Deka R, Jin L: Genome amplification of single sperm using multiple displacement amplification. Nucleic Acids Res 2005, 33:e91.

32. Okuducu AF, Hahne JC, Von Deimling A, Wernert N: Laserassisted microdissection, techniques and applications in pathology (review). Int J Mol Med 2005, 15:763-769.

33. Heinmoller E, Liu O, Sun Y, Schlake G, Hill KA, Weiss LM, Sommer SS: Toward efficient analysis of mutations in single cells from ethanol-fixed, paraffin-embedded, and immunohistochemically stained tissues. Lab Invest 2002, 82:443-453.

34. Westphal G, Burgemeister R, Friedemann G, Wellmann A, Wernert N, Wollscheid V, Becker B, Vogt T, Knuchel R, Stolz W, Schutze K: Noncontact laser catapulting: a basic procedure for functional genomics and proteomics. Methods Enzymol 2002, 356:80-99.

35. Heinmoller E, Bockholt A, Werther M, Ziemer M, Muller A, Ghadimi $B M$, Ruschoff J: Laser microdissection of small tissue samples-application to chronic pancreatitis tissues. Pathol Res Pract 2003, 199:363-371.

36. Pamphlett R, Heath PR, Holden H, Ince PG, Shaw PJ: Detection of mutations in whole genome-amplified DNA from lasermicrodissected neurons. J Neurosci Methods 2005, 147:65-67.

37. Agar NS, Halliday GM, Barnetson RS, Ananthaswamy HN, Wheeler $M$, Jones AM: The basal layer in human squamous tumors harbors more UVA than UVB fingerprint mutations: a role for UVA in human skin carcinogenesis. Proc Natl Acad Sci U S A 2004, I 0 I:4954-4959.

38. Wang VW, Bell DA, Berkowitz RS, Mok SC: Whole genome amplification and high-throughput allelotyping identified five distinct deletion regions on chromosomes 5 and 6 in microdissected early-stage ovarian tumors. Cancer Res 2001, 61:4169-4I74.

39. Rook MS, Delach SM, Deyneko G, Worlock A, Wolfe JL: Whole genome amplification of DNA from laser capture-microdissected tissue for high-throughput single nucleotide polymorphism and short tandem repeat genotyping. Am J Pathol 2004, 164:23-33.

40. Hughes S, Yoshimoto M, Beheshti B, Houlston RS, Squire JA, Evans A: The use of whole genome amplification to study chromosomal changes in prostate cancer: insights into genome-wide signature of preneoplasia associated with cancer progression. BMC Genomics 2006, 7:65

41. Fassunke J, Majores M, Ullmann C, Elger CE, Schramm J, Wiestler OD, Becker AJ: In situ-RT and immunolaser microdissection for mRNA analysis of individual cells isolated from epilepsyassociated glioneuronal tumors. Lab Invest 2004, 84:I520-I525. 
42. Keays KM, Owens GP, Ritchie AM, Gilden DH, Burgoon MP: Laser capture microdissection and single-cell RT-PCR without RNA purification. J Immunol Methods 2005, 302:90-98.

43. Burgoon MP, Keays KM, Owens GP, Ritchie AM, Rai PR, Cool CD, Gilden DH: Laser-capture microdissection of plasma cells from subacute sclerosing panencephalitis brain reveals intrathecal disease-relevant antibodies. Proc Natl Acad Sci U S A 2005, 1 02:7245-7250.

44. Seitz S, Schneider CK, Malotka J, Nong X, Engel AG, Wekerle H, Hohlfeld R, Dornmair K: Reconstitution of paired T cell receptor alpha- and beta-chains from microdissected single cells of human inflammatory tissues. Proc Natl Acad Sci U S A 2006, I 03: | 2057-|2062.

45. Wang K, Lau TY, Morales M, Mont EK, Straus SE: Laser-capture microdissection: refining estimates of the quantity and distribution of latent herpes simplex virus I and varicella-zoster virus DNA in human trigeminal Ganglia at the single-cell level. J Virol 2005, 79:|4079-|4087.

46. Walsh PS, Erlich HA, Higuchi R: Preferential PCR amplification of alleles: mechanisms and solutions. PCR Methods Appl 1992, I:24I-250.

47. Baker SM, Plug AW, Prolla TA, Bronner CE, Harris AC, Yao X, Christie DM, Monell C, Arnheim N, Bradley A, Ashley T, Liskay RM: Involvement of mouse MIhI in DNA mismatch repair and meiotic crossing over. Nat Genet 1996, 13:336-342.

48. Brownie I, Shawcross S, Theaker J, Whitcombe D, Ferrie R, Newton $C$, Little S: The elimination of primer-dimer accumulation in PCR. Nucleic Acids Res 1997, 25:3235-324I.

49. Hosono S, Faruqi AF, Dean FB, Du Y, Sun Z, Wu X, Du J, Kingsmore SF, Egholm M, Lasken RS: Unbiased whole-genome amplification directly from clinical samples. Genome Res 2003, I 3:954-964.

50. Garvin AM, Holzgreve W, Hahn S: Highly accurate analysis of heterozygous loci bysingle cell PCR. Nucleic Acids Res 1998, 26:3468-3472.

51. Renwick PJ, Lewis CM, Abbs S, Ogilvie CM: Determination of the genetic status of cleavage-stage human embryos by microsatellite marker analysis following multiple displacement amplification. Prenat Diagn 2007, 27:206-2I5.

52. Spits C, Le Caignec C, De Rycke M, Van Haute L, Van Steirteghem A, Liebaers I, Sermon K: Whole-genome multiple displacement amplification from single cells. Nat Protoc 2006, I: I965-1970.

53. Persson AE, Ling G, Williams C, Backvall H, Ponten J, Ponten F, Lundeberg J: Analysis of p53 mutations in single cells obtained from histological tissue sections. Anal Biochem 2000, 287:25-3I.

54. Stoecklein NH, Erbersdobler A, Schmidt-Kittler O, Diebold J, Schardt JA, Izbicki JR, Klein CA: SCOMP is superior to degenerated oligonucleotide primed-polymerase chain reaction for global amplification of minute amounts of DNA from microdissected archival tissue samples. Am J Pathol 2002, I 6 I:43-5I.

55. Frumkin D, Wasserstrom A, Kaplan S, Feige U, Shapiro E: Genomic variability within an organism exposes its cell lineage tree. PLoS Comput Biol 2005, I:e50.

56. Shibata $D$, Tavare $S$ : Counting divisions in a human somatic cell tree: how, what and why? Cell Cycle 2006, 5:610-614.

57. Salipante S], Horwitz MS: A phylogenetic approach to mapping cell fate. Curr Top Dev Biol 2007, 79:157-I84.

58. Shibata D, Tavare S: Stem cell chronicles: autobiographies within genomes. Stem Cell Rev 2007, 3:94- 103.

59. Dalerba P, Cho RW, Clarke MF: Cancer stem cells: models and concepts. Annu Rev Med 2007, 58:267-284.

60. Mueller MM, Fusenig NE: Friends or foes - bipolar effects of the tumour stroma in cancer. Nat Rev Cancer 2004, 4:839-849.

61. Kunieda T, Xian M, Kobayashi E, Imamichi T, Moriwaki K, Toyoda Y: Sexing of mouse preimplantation embryos by detection of $Y$ chromosome-specific sequences using polymerase chain reaction. Biol Reprod 1992, 46:692-697.

62. Dai JG, Lei X, Min JX, Zhang GQ, Wei H: Mitochondrial DNA sequence analysis of two mouse hepatocarcinoma cell lines. World J Gastroenterol 2005, I I:264-267.

63. Primer3 [http://frodo.wi.mit.edu/cgi-bin/primer3/ primer3 www.cgi]
Publish with Biomed Central and every scientist can read your work free of charge

"BioMed Central will be the most significant development for disseminating the results of biomedical research in our lifetime. "

Sir Paul Nurse, Cancer Research UK

Your research papers will be:

- available free of charge to the entire biomedical community

- peer reviewed and published immediately upon acceptance

- cited in PubMed and archived on PubMed Central

- yours - you keep the copyright

Submit your manuscript here:

http://www.biomedcentral.com/info/publishing_adv.asp
BiolMedcentral 